\title{
Политическая пропаганда в Курской губернии во второй половине XIX - начале XX в.
}

\author{
К.А. Зарубина \\ Юго-Западный государственный университет, \\ Россия, 305040, г. Курск, ул. 50 лет октября, 94 \\ E-mail: kris1996z@mail.ru
}

\begin{abstract}
Аннотация. Цель исследования - анализ проблемы воздействия политических партий, движений, кружков на общественное сознание населения посредством использования различных форм пропаганды в Курской губернии во второй половине XIX - начале XX в., изучение основных технологий политического «просвещения», методов формирования антимонархических настроений в обществе. Приёмы политической пропаганды рассматриваются в исторической ретроспективе. В процессе исследования нами были использованы методы анализа, синтеза, обобщения и систематизации, хронологический и сравнительно-правовой метод. Основные выводы, представленные в статье, основываются на данных архивных источников. В заключении подводятся итоги манипуляции общественно-политическим сознанием, возможности быстрой мобилизации темного крестьянства и зарождающегося рабочего класса в ответ на политическую пропаганду.
\end{abstract}

Ключевые слова: политическая пропаганда, воззвания, революционные листовки, общественнополитическое сознание, общественно-политические движения.

Для цитирования: Зарубина К.А. 2020. Политическая пропаганда в Курской губернии во второй половине XIX - начале XX в. Via in tempore. История. Политология, 47 (3): 552-558. DOI 10.18413/2687-0967-2020-47-3-552-558.

\section{Political propaganda in the Kursk province in the second half of the XIX beginning of the XX century}

\author{
Kristina A. Zarubina \\ South-West State University, \\ 9450 let oktyabrya St., Kursk, 305040, Russia \\ E-mail: kris1996z@mail.ru
}

\begin{abstract}
The purpose of the research is to analyze the impact of political parties, movements, and circles on the public consciousness of the population through the use of various forms of propaganda in the Kursk province in the second half of the XIX - early XX century, the study of the main technologies of political «enlightenment», methods of forming anti-monarchic attitudes in society. Methods of political propaganda are considered in historical retrospect. In the process of research we used methods of analysis, synthesis, generalization and systematization, chronological and comparative legal methods. The main conclusions presented in the article are based on data from archival sources. In conclusion, we summarize the manipulation of socio-political consciousness, the possibility of rapid mobilization of the dark peasantry and the emerging working class in response to political propaganda. In addition, the article analyzes in detail some methods of working with the population aimed at political education of the masses. For example, the article discusses in detail methods of distributing leaflets with anti-government content in rural areas, as well as other methods of working with the population.
\end{abstract}

Keywords: political propaganda, proclamations, revolutionary leaflets, social and political consciousness, social and political movements. 
For citation: Zarubina K.A. 2020. Political propaganda in the Kursk province in the second half of the XIX beginning of the XX century. Via in tempore. History and political science, 47 (3): 552-558 (in Russian). DOI 10.18413/2687-0967-2020-47-3-552-558.

Единого теоретического подхода к анализу сущности политической пропаганды в настоящее время не существует, как признают большинство исследователей [Порецкова, 2015, с. 19-33]. В историческом ракурсе данный институт представляет интерес, поскольку политическая пропаганда в дореволюционный период была отличным средством для мобилизации и тёмного крестьянства, и зарождающегося класса рабочих. Народовольцы так определяли смысл этого важного мероприятия: «Писать, писать много и понятно народу; заводить тайные типографии, распространять печатное...» [Серно-Соловьевич, 1963, с. 234-239]. Редактор известного в XIX в. оппозиционного журнала «Вперёд» замечал: «Пропаганда революционная обнимает и предполагает агитацию» [Русской социально-революционной, 1874, с. 32-33; Вперёд, 1876, с. 195].

Теорией пропаганды во второй половине XIX в. занимался и известный русский философ, революционер П.Л. Лавров. Он поддерживал идею о необходимости просвещения населения через использование возможных пропагандистских средств и верил, что реализация идеала жизни связана с духовным воздействием меньшинства (интеллигенции) на общество [Юдин, 2012, с. 237-242]. В работе «Исторические письма» учёный формулировал программу широкого народного просвещения, где ведущая роль отводилась борьбе с невежеством и насаждению политической грамотности [Мелехин, 2009, с. 42-46; Миланов, 2018, с. 37-47]. Проблемам политической пропаганды в контексте изучения различных исторических событий были посвящены и исследования современных учёных [Салтык, 2007, с. 126-130; Квасов, 2009, с. 214-218; Косихина, 2009, с. 401-413; Салтык, 2010, с. 61-67; Степанова, 2010, с. 68-74; Квасов, 2011, с. 165-172].

В этом контексте обратим особое внимание на то, что в рассматриваемый период времени речь идёт именно о пропаганде, а не об агитации, поскольку распространение листовок, обращений, воззваний к народу и т. п. было нацелено лишь на просвещение населения в «нужном» общественно-политическом русле, а не на конкретное побуждение к действию, результат [Макаров, 2008, с. 77; Тимко, Жайворонок, 2013, с. 43-47]. Вследствие этого заметим, что об активной агитации народных масс следует говорить позднее, ближе к революционным событиям начала XX в., когда станут появляться различные призывы к открытому неповиновению власти и т. п.

В процессе исследования нами были использованы методы анализа, синтеза, обобщения и систематизации, хронологический и сравнительно-правовой методы. Методология исследования основана на основополагающих принципах исторического познания: принципе историзма, объективности, системном и ценностном подходе, проблемнохронологическом принципе.

Политическая пропаганда имела место во второй половине XIX - начале XX в. не только в крупных городах, но и в провинции. Несмотря на то, что известное «хождение в народ» 1870-х гг. фактически провалилось в связи со всеобщим недоверием населения (особо крестьянства) к «пришлым» агитаторам [Майшев, 2016, с. 14-19], просвещение народных масс продолжилось.

В Курской губернии в рассматриваемый период были сильны «традиции» социально-политического просвещения населения. По сообщению Департамента полиции МВД, во второй половине XIX в. интеллигенция активно внедрялась в народные массы, занимаясь пропагандой. Учащаяся молодёжь направлялась «в народ», например, в помощь медицинскому персоналу для борьбы с разными эпидемиями. Лица запасались при отправле- 
нии в сельскую местность необходимым материалом: брошюрами для народного чтения, антиправительственными воззваниями, программами и т. п. ${ }^{61}$

Как сообщало МВД, в рассматриваемый период времени из разных регионов Российской империи (в том числе и из Курской губернии) регулярно поступали сведения о продолжающейся усиленной рассылке «опасных» листовок и брошюр. Некоторые политически неблагонадёжные лица осознавали несбыточность своих преступных «вожделений» и хотели «произвести смуту в общественных слоях», прикрываясь даже именем несуществующих в действительности революционных групп и организаций различных наименований, рассылая по почте опасные воззвания. ${ }^{62}$ Пограничные территории выступали перевалочными базами для переправки в Россию литературы из-за рубежа. Особое внимание было уделено южным регионам страны, поскольку оттуда распространять листовки, брошюры и т. п. было как нельзя удобно (в основном с помощью морских путей сообщения) [Пасечников, 2013, с. 125-142].

Курская губерния не оставалась в стороне от текущего прогресса. Этому способствовала разветвлённая сеть железных дорог, а также относительная близость к границам. Так, по сообщению епископа Курского и Белгородского (а именно по донесению курского епархиального противосектанского миссионера, священника Иоанна Дмитриевского), крестьянин с. Кульбак Рыльского уезда С.Ф. Колесниченков в 1901 г. секретно получал письма из толстовской брошюрки заграничного издания (из Англии). По показаниям свидетелей, издание «Свободное слово» было направлено на ниспровержение существующего порядка. Крестьянина в связи с этим подозревали в сочувствии социализму толстовского типа. Кроме того, обвиняемый, по заявлению епископа, был сектантом. Указанную литературу С.Ф. Колесниченков читал в избе крестьянина С.М. Верхоглядова в присутствии разных лиц. По показаниям свидетелей, крестьянин О.Г. Иляшенко также приносил какието запрещённые книги. У данных лиц был произведён обыск и изъяты конверт с заграничным адресом и листки с записанными адресами, но запрещённой литературы не обнаружено. На время дознания С.М. Верхоглядова заключили под стражу в Рыльскую тюрьму, однако вскоре за неимением состава преступления, предусмотренного ст. 252 (хранение, составление и распространение печатных и письменных сочинений), освободили. ${ }^{63}$

Обычно запрещённую литературу политического характера читали публично. Основными слушателями были крестьяне, поскольку данная часть населения была необразованной, им приходилось всё разъяснять. В Курской губернии встречались случаи публичного прочтения революционных воззваний в присутствии сельских старост. Так, в 1901 г. И.Н. Машков, крестьянин с. Верхней Соковнинки, читал односельчанам письма «о прирезке земли мужикам», которые ему передавал некто А. Татаринов. ${ }^{64}$ В том же 1901 г. крестьянин Ямской слободы Курского уезда С.Г. Масленников распространял революционные воззвания, передавал их для чтения рабочим. ${ }^{65}$

В начале XX в. в Курской губернии стали распространяться прокламации, воззвания революционного характера так называемым пассивным способом. Листки с оппозиционными идеями запечатывали в небольшие конверты и разносили по городу. Обнаружить их можно было в разных местах. Например, 4 марта 1901 года с забора на Ендовищенской улице г. Курска конторщиком железнодорожной станции курским мещанином В.Н. Афанасьевым было снято воззвание к гражданам с призывом к бунту. ${ }^{66}$ Прокурор Харьковской судебной палаты, вследствие дошедших до него сведений о том, что в г. Курске были расклеены прокламации, описывающие в превратном виде случаи столкно-

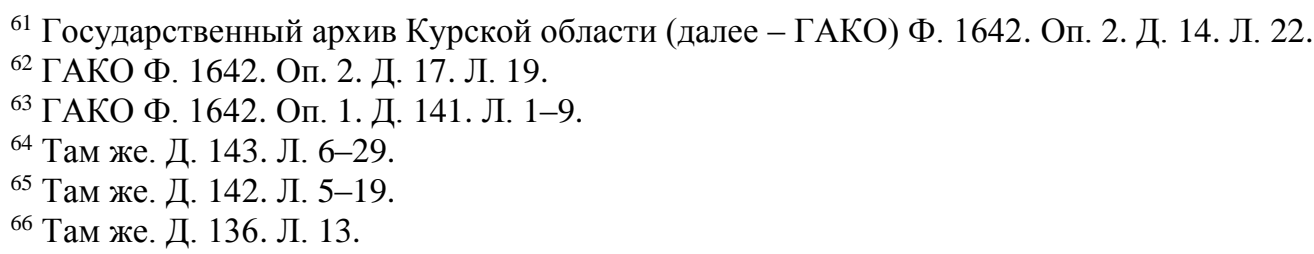


вения студентов с чинами полиции, призывающие народ к непослушанию правительства и требующие созыва великого Земского Собора, поручил принять к сведению упомянутые воззвания Начальнику Курского губернского жандармского управления. ${ }^{67}$

Содержание таких обращений действительно было политически опасным. Вот отрывок одного из них: «Министры спели, будто народ во всём доволен и во всём виновата легкомысленная молодежь из студенчества. Это ложь, на которую так щедры министры. Обманом держится их подлость, казнокрадство, и обманом же и силой они хотят зажать рот раздражённого народа... Исстрадавшийся, обнищавший народ громко заявит свои права на лучшую жизнь и силой возьмёт то, что ему не дают...». ${ }^{68}$ Из другого воззваниялистовки петербургских рабочих курским рабочим: «Товарищи! Дадим же знать нашему деспоту и тирану, Николаю Второму, что русский рабочий не пешка, не скот, а человек... Кровь убитых братьев зовет нас ко мщению. Ко мщению, товарищи, ко мщению...». 69

В 1902 г. на станции Курск было обнаружено воззвание «Русские люди» (по доносу местного крестьянина). Виновные в распространении листовки найдены не были. ${ }^{70}$

В том же году в Рыльском уезде Курской губернии был найден один печатный экземпляр воззвания революционного содержания под наименованием «Братия крестьяне» (по донесению крестьянина И.Ф. Ефименко); в Обоянском уезде - книжка «Письмо ко всему русскому крестьянству. Устав крестьянского союза. Братство для защиты народного права». ${ }^{71}$

Так как распространители использовали железную дорогу и в связи с участившимися случаями обнаружения таких находок на поездах, розыскная деятельность активизировалась на железнодорожных станциях. Кондукторы поездов отчитывались о составе пассажиров поезда, а именно о том, были ли среди них интеллигенты. Нередко, согласно опросам уполномоченных органов, горничные отмечали странности в поведении отдельных пассажиров. Иногда в распространении опасных листовок подозревали дам. Например, в 1902 г. в пределах Курской губернии на разъезде № 34 крестьянин Льговского уезда с. Марица видел, как молодая женщина выбросила листовки из поезда, после поднял четыре прокламации и доложил о случившемся полиции. ${ }^{72}$

В это же период времени в Курской губернии начинает интенсивную политическую агитацию Российская социал-демократическая партия. Так, в 1902 г. в одном из присутственных мест были найдены экземпляры воззвания следующего содержания: «Весть о целом ряде уличных демонстраций в Петербурге, Москве, Киеве, Харькове, Екатеринославле, Тифлисе и других городах облетела всю Россию. Тщетно правительство силится искоренить и замолчать факты. Тщетно грозные стремления задернет революционная буря... (Российская социал-демократическая партия)». ${ }^{73}$ В том же 1902 г. была найдена другая листовка, содержащая переписку между тайными студенческими объединениями: «Письма о харьковских и екатеринославских демонстрациях, полученные ещё до Рождества, мы не могли выслать по обстоятельствам, от нас независящим. Теперь же мы надеемся дать подробный отчет о всех событиях... 29 января 1902 г.». ${ }^{74}$

Однако распространение листовок было недостаточно эффективным, поскольку смысл таких сообщений без должного разъяснения понимали немногие. Вследствие чего печатные материалы проигрывали в оперативности, поскольку часто воспринимались малограмотными людьми неадекватно (так же как и в более поздние периоды времени) [Ба-

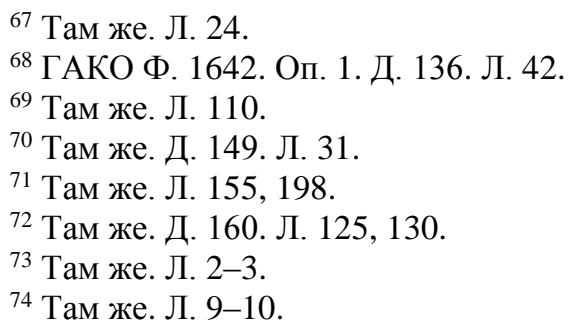


ришполец, 2014, с. 52-79]. Так, в Курской губернии в Колоденской волости в 1902 г. некто, обнаружив записки на путевой стороне, не придал им серьёзного значения, а подумал, что из поезда выбросили «бумагу на папироски», так как и раньше были случаи, что ему по его просьбе машинисты и кондукторы бросали из поездов папиросную бумагу. В дальнейшем листовки поступили в полицию, а пути осмотрены на предмет обнаружения иных противоправительственных брошюр. ${ }^{75}$

В Курской губернии в рассматриваемый период использовались разные «технологии» политической пропаганды. Основной целью такого «просвещения» было информирование населения о наиболее важных общественно-политических вопросах. Однако в распространяемой литературе нередко освещались и экономические отношения (естественно, в негативном свете). «Хождение в народ» в Курской губернии, так же как и в иных регионах, не дало положительного результата, в связи с чем лидеры общественнополитических движений обратились к более сдержанным формам пропаганды. В политическом дискурсе это понималось как распространение определённых антиправительственных взглядов, идей с целью формирования нужного общественно-политического сознания, подготовки населения к грядущей революции.

В основном политическая пропаганда в Курской губернии во второй половине XIX - начале XX в. выражалась в двух формах: чтении и разъяснении оппозиционной литературы (в том числе посланной из-за границы), распространении листовок с политическим содержанием. Однако если к чтению многие относились благосклонно или хотя бы нейтрально, то найденные конверты с «опасным» и, в первую очередь, непонятным для необразованных или малообразованных народных масс текстом, как правило, относили в полицию. Многие отдавали листовки сельским старостам, иным государственным служащим просто потому, что не могли прочесть эти сообщения, поскольку, как мы уже отмечали выше, большая часть населения в губернии была неграмотной.

Таким образом, проанализировав данные архивных материалов, мы можем отметить, что политическая пропаганда (общественно-политическое «просвещение») в Курской губернии во второй половине XIX - начале XX в. велась достаточно активно. Однако быстро мобилизовать темное крестьянство и зарождающийся рабочий класс у пропагандистов не получилось. Вероятно, в будущем именно это повлияло на относительно стабильное положение губернии и неучастие большей части населения в революционных событиях, гражданской войне. Поэтому пропаганда в Курском регионе в столь сдержанных формах не стала мощным средством манипуляции общественно-политическим сознанием.

\section{Список литературы}

1. Баришполец В.А. 2014. Области применения информационно-психологического воздействия. Москва, РЭНСИТ, 79.

2. Вперёд: двухнедельное обозрение. (Год второй). 1876. Первое полугодие. Лондон. 25-36: 157.

3. Квасов О. Н. 2009. Структурные субъекты российского революционного терроризма начала XX века. Вестник ВГУ. Серия: Лингвистика и межкультурная коммуникация. Выпуск 2. 214-218.

4. Квасов О.Н. 2011. Террористический компонент социально-политических процессов в Курской губернии начала XX века. Научные ведомости Белгородского государственного университета. Серия: История. Политология. 19 (114): 165-172.

5. Косихина И.Г. 2009. Общественно-культурные организации в губернском городе конца XIX-начала XX в. (на примере Курска). Культура городов Российской империи на рубеже XIX XX веков (Материалы международного коллоквиума, Санкт-Петербург, 14-17 июня, 2004 года). СПб.: Издательство Европейский Дом: 401-413.

${ }^{75}$ ГАКО Ф. 1642. Оп. 1. Д. 160. Л. 44-45. 
6. Майшев С.Е. 2016. Возникновение политического терроризма в Российской Империи во второй половине XIX века. Kant. 1 (18): 14-19.

7. Макаров В.П. 2008. Общественная мысль в России XIX - начала XX вв.: история, историография, источниковедение: (работы разных лет). Нижний Новгород, ННГАСУ, 192.

8. Мелехин В.И. 2009. «Исторические письма» Петра Лаврова: современное прочтение. Дискурс-Пи. 1 (1): 42-46.

9. Милованов К.Ю. 2018. Просветительская идеология русского народничества. Отечественная и зарубежная педагогика. 4 (53): 37-47.

10.Пасечников И.А. 2013. Становление и развитие органов политической полиции Севастополя в XIX веке. Ученые записки Крымского федерального университета имени В.И. Вернадского. Исторические науки. 2 (1): 125-142.

11.Порецкова А.А. 2015. Концептуализация теоретических подходов к изучению политической пропаганды. Контуры глобальных трансформаций: политика, экономика и право. 2 (40): 19-33.

12. Русской социально-революционной молодежи. По поводу брошюры: «Задачи революционной пропаганды въ России». 1874. Редактора журнала «Впередъ» [P.L. Lavrov]. Лондон, Наборная журнала «Вперёд», 158.

13. Салтык Г. А. 2007. «За землю и волю...» (к вопросу о неонародническом движении в Центральном Черноземье). Ученые записки. Электронный научный журнал Курского государственного университета. Выпуск 2. 126-130.

14. Салтык Г. А. 2010. Народные социалисты Центрального Черноземья: история становления и деятельности (конец XIX начало XX в.). Ученые записки. Электронный научный журнал Курского государственного университета. Выпуск 3 (15). 61-67

15. Серно-Соловьевич Н.А. 1963. Ответ «Великоруссу». Публицистика. Письма, М., Наука, 431.

16. Степанова Е. И. 2010. К вопросу о становлении полицейской стражи Курской губернии. Ученые записки. Электронный научный журнал Курского государственного университета. Выпуск 3 (15): 68-74.

17. Тимко С.А., Жайворонок А.В. 2013. Пропаганда и агитация в деятельности органов внутренних дел. Психопедагогика в правоохранительных органах. 4 (55): $43-47$.

18. Юдин А.И. 2012. П.Л. Лавров о проблеме: интеллигенция и народ, интеллигенция и власть. Вестник ТГУ. 7 (7): 237-242.

\section{References}

1. Barishpolec V.A. 2014. Oblasti primenenija informacionno-psihologicheskogo vozdejstvija [Areas of application of information and psychological impact]. Moscow, RJeNSIT. 1 (1): 52-79 (in Russian).

2. Vperjod: dvuhnedel'noe obozrenie. (God vtoroj). 1876 [Forward: two-week review. (Year two)]. Pervoe polugodie. London, 25-36: 157.

3. Kvasov O. N. 2009. Ctrukturnyie sub'ektyi rossiyskogo revolyutsionnogo terrorizma nachala XX veka [Structural subjects of Russian revolutionary terrorism of the beginning of the XX century.] Vestnik VGU. Seriya: Lingvistika i mezhkulturnaya kommunikatsiya. Vyipusk 2: 214-218 (in Russian).

4. Kvasov O.N. 2011. Terroristicheskiy komponent sotsialno-politicheskih protsessov v Kurskoy gubernii nachala XX veka [The terrorist component of socio-political processes in the Kursk province at the beginning of the XX century. Scientific Bulletin of the Belgorod state University]. Nauchnyie vedomosti Belgorodskogo gosudarstvennogo universiteta. Seriya: Istoriya. Politologiya. 19 (114): 165172 (in Russian).

5. Kosihina I.G. 2009. Obschestvenno-kulturnyie organizatsii v gubernskom gorode kontsa XIX-nachala XX v. (na primere Kurska). Kultura gorodov Rossiyskoy imperii na rubezhe XIX - XX vekov [Social and cultural organizations in the provincial city of the late XIX-early XX century. (for example, Kursk). Culture of cities of the Russian Empire at the turn of the XIX-XX centuries] (Materialyi mezhdunarodnogo kollokviuma, Sankt-Peterburg, 14-17 iyunya, 2004 goda). SPb.: Izdatelstvo Evropeyskiy Dom: 401-413 (in Russian).

6. Majshev S.E. 2016. Vozniknovenie politicheskogo terrorizma v Rossijskoj Imperii vo vtoroj polovine XIX veka [The emergence of political terrorism in the Russian Empire in the second half of the XIX century]. Kant. 1 (18): 14-19 (in Russian). 
7. Makarov V.P. 2008. Obshhestvennaja mysl' v Rossii XIX - nachala XX vv.: istorija, istoriografija, istochnikovedenie: (raboty raznyh let) [Public thought in Russia of the XIX - early XX centuries: history, historiography, source studies: (works of different years)]. Nizhnij Novgorod. NNGASU, 192 (in Russian).

8. Melehin V.I. 2009. «Istoricheskie pis'ma» Petra Lavrova: sovremennoe prochtenie. [Historical letters by Peter Lavrov: a modern reading]. Diskurs-Pi. 1 (1): 42-46 (in Russian).

9. Milovanov K.Ju. 2018. Prosvetitel'skaja ideologija russkogo narodnichestva. Otechestvennaja i zarubezhnaja pedagogika [Educational ideology of Russian populism. Domestic and foreign pedagogy]. 4 (53): 37-47 (in Russian).

10. Pasechnikov I.A. 2013. Stanovlenie i razvitie organov politicheskoj policii Sevastopolja v XIX veke [Formation and development of the political police of Sevastopol in the XIX century]. Uchenye zapiski Krymskogo federal'nogo universiteta imeni V.I. Vernadskogo. Istoricheskie nauki. 2 (1): 125-142 (in Russian).

11. Poreckova A.A. 2015. Konceptualizacija teoreticheskih podhodov k izucheniju politicheskoj propagandy [Conceptualization of theoretical approaches to the study of political propaganda]. Kontury global'nyh transformacij: politika, jekonomika, pravo. 2 (40): 19-33 (in Russian).

12. Russkoj social'no-revoljucionnoj molodezhi. Po povodu broshjury: «Zadachi revoljucionnoj propagandy v Rossii». 1874 [Russian social-revolutionary youth. About the brochure: «Tasks of revolutionary propaganda in Russia»]. Redaktora zhurnala «Vpered» [P.L. Lavrov]. London. Nabornaja zhurnala «Vperjod», 158 (in Russian).

13. Saltyik G. A. 2007. «Za zemlyu i volyu...» (k voprosu o neonarodnicheskom dvizhenii v Tsentralnom Chernozeme) [«For land and freedom...» (on the question of the neo-national movement in the Central Chernozem region)]. Uchenyie zapiski. Elektronnyiy nauchnyiy zhurnal Kurskogo gosudarstvennogo universiteta. Vyipusk 2. 126-130 (in Russian).

14. Saltyik G. A. 2010. Narodnyie sotsialistyi Tsentralnogo Chernozemya: istoriya stanovleniya i deyatelnosti (konets XIX-nachalo XX v.) [People's socialists of the Central Chernozem region: history of formation and activity (late XIX-early XX century)]. Uchenyie zapiski. Elektronnyiy nauchnyiy zhurnal Kurskogo gosudarstvennogo universiteta. Vyipusk 3 (15). 61-67 (in Russian).

15. Serno-Solov'evich H.A. 1963. Otvet «Velikorussu» [The Answer To The «Great Russians»]. Publicistika. Pis'ma. Moscow, Nauka, 431 (in Russian).

16. Stepanova E. I. 2010. K voprosu o stanovlenii politseyskoy strazhi Kurskoy gubernii [To the question of the formation of the police guard of the Kursk province]. Uchenyie zapiski. Elektronnyiy nauchnyiy zhurnal Kurskogo gosudarstvennogo universiteta. Vyipusk 3 (15): 68-74 (in Russian).

17. Timko S.A., Zhajvoronok A.V. 2013. Propaganda i agitacija v dejatel'nosti organov vnutrennih del [Propaganda and agitation in the activities of internal Affairs bodies]. Psihopedagogika $v$ pravoohranitel'nyh organah. 4 (55): 43-47 (in Russian).

1. Judin A.I. 2012. P.L. Lavrov o probleme: intelligencija i narod, intelligencija i vlast' [P.L. Lavrov on the problem: the intelligentsia and the people, the intelligentsia and the government]. Vestnik TGU. 7 (7): 237-242 (in Russian).

\section{ИНФОРМАЦИЯ ОБ АВТОРЕ}

\author{
Зарубина Кристина Александровна, \\ аспирант кафедры истории и социально- \\ культурного сервиса Юго-Западного \\ государственного университета, г. Курск, \\ Россия
}

\section{INFORMATION ABOUT THE AUTHOR}

Kristina A. Zarubina, post-graduate student of the Department of history and socio-cultural service of the South-Western state University, Kursk, Russia 